\title{
Beach Body Work: Australian Women's Experiences
}

\begin{abstract}
This paper examines Australian women's complex relationship with the beach through a focus on affect and on what bodies do. Interviews with ten participants of diverse backgrounds and of different ages reveal that women understand the beach as a mediated and surveilled space where their bodies are foregrounded. In this environment, there is an intersection of women's knowledge of the popular constructions of the archetypal Australian beach body, real women's bodies, and interviewees' experiences of the beach as a place of shame and pride. As a means of managing this affective landscape participants detail a range of bodily strategies enacted prior to going to the beach and once at the beach. This bodily labour demonstrates that for Australian women the beach is a dynamic and complicated site of both leisure and labour.
\end{abstract}

\section{Keywords}

pride, shame, bodies, women, suburban beach, body work

\section{Introduction}

Just as the beach is an Australian icon (Fiske et al., 1987; Bonner et al., 2001), so is its revealing national costume, as well as the body that wears it (Craik, 2010). Khamis $(2010,384)$ asserts that 'one of the most salient representations of Australian beach culture' is 'the beach babe' who is 'often (but not always) blonde, blue-eyed and bikinied'. However, even though 'successfully' wearing a swimsuit or bikini at the beach requires a rigorously prepared body (Booth, 2001, 18), the implications of this requirement are seldom acknowledged. The 'beach body' is currently understood in popular culture as an aspirational body which one can be proud to flaunt at the beach, and is promoted by the health and beauty industries as a body which is healthy, free and empowered. The image of the 'beach body' is perhaps most recognisable in media 
images, however there has been very little interest in the effects of 'beach body' rhetoric. This is despite the existing literature which has firmly established the harmful relationship between body image and traditional media (Duncan and Klos, 2014), body image and social media (Fernandez, 2012; Perloff, 2014), and the effects of an idealised swimmer's body on women's relationship with their bodies (McMahon, Penney, DinanThompson, 2012; McMahon and Dinan-Thompson, 2011).

Small's (2017) textual analysis of beach bodies in Australian lifestyle magazines, and Jordan's (2007) research drawing on data from the United Kingdom, are two exceptions to this lacuna. In these studies, the authors find that constructions of the 'beach body' are profoundly gendered. As Jordan $(2007,103)$ observes, magazines 'define the appropriate (female) physical form for display in the holiday context', and moreover, convey the 'implicit message' that such a body is a prerequisite to public tourist spaces. This invites us to question how diverse women, whose bodies do not necessarily adhere to the popular understanding of the 'beach body', experience the beach space. Jordan (2007) and Small's (2017) studies provide useful insights into dominant depictions of the ideal women's holiday/leisure body, but as they both note, they are textual only and thus what they miss are the voices of the beach-goers themselves - not only as tourists, but as locals.

Arguably, a focus on how women experience their bodies at the beach is particularly apposite in the Australian context given that we are imagined to be 'outdoor types' and 'beachgoers all of us' (Pettigrew 2002). Such a perception highlights Fiske, Hodge and Turner's $(1987,58)$ observation that the Australian beach exists within the social and cultural, as well as the natural world. They suggest that the myth of the ideal Australian beach is 'classless, matey, basic, natural'. Ellison $(2013,164)$ has continued this analysis of the place of the beach in the national psyche noting its 'imagined democracy' is highly contestable.

Most pertinent to Ellison's (2013) thesis is the history of Australian colonialism and the conflicts which have taken place on the beach between settlers and Aboriginal and Torres Strait Islander peoples. Lambert's $(2010,308)$ assertion that the process of constructing a white nation, 'entailed the privileging of certain relationships to space 
and a deliberate obscuring of others' is manifest in terms of the idealisation of the beach in Australia. As Metusela and Waitt (2012) reveal in their cultural geography of the Australian beach, the Aboriginal language groups living in and around the beaches of the Illawarra district, and the centrality of the seaside to their culture, have been erased in colonial narratives. More recently, the Australian beach has been a site of racialised boundary marking and containment in relation to refugees and asylum seekers (Lobo 2014; Noble and Poynting 2010; Hartley and Green 2006).

In mapping inclusions and exclusions in Australian beach culture from the colonial period onwards, Metusela and Waitt (2012) use the scale of the body. They argue that since its transformation in the early twentieth century from a place where daylight bathing was banned to a place of hedonistic and health inducing popularity, the Australian beach has centred on bodies. In charting this beach/body nexus further Crombie $(2004,176)$ writes that the growing popularity of 'body culture' and eugenics in the 1930s, rendered the beach 'a venue for the middle-classes to show off the latest in beach fashions; the location of unconscious (or conscious) sexual forces; and a place to re-establish physical vitality'. Adding a gendered dimension to this discussion of embodiment and the beach in Australia, writers such as Craik (2010) and Schmidt (2012) have attended to shifts in fashion celebrating the liberation of women from heavy, dangerous and prudish swimwear.

A more explicitly feminist perspective to the bodily beach experiences of Australian women is taken by Barcan (2001) in a study of female nudity and the gaze, and by Nash (2016) in research on pregnant women's beach memories. In the former Barcan (2001, 305) argues that the nudist beach offers women a place where they can 'opt out of the relentlessly comparative or competitive looking' that occurs on 'clothed' beaches. This observation suggests that there are complex affective relations at play in women's embodied beach going. Such a finding resonates with Nash's $(2016,15)$ analysis of pregnant bikini photos at the beach which she says, citing Rose $(2010,44)$, have a specific 'affective stance'. She writes that these photographs recognise the power of the gaze (of self and others), and are used to convey an aesthetic of the pregnant body as 
natural and authentic. They are also central to constructions of white, middle-class notions of family and nation.

The feminist concern with investigating the intersections between body and beach, and the affective dimensions of these intersections exemplified by the work of Barcan (2001) and Nash (2016), are furthered in this paper through interviews with women about their everyday experiences of beach going. In doing so we engage with broader agendas in feminist geography about the need to consider affect in the spatial production of gendered identities and in the reproduction of gendered inequalities (e.g. Lean and Staiff 2016). Thus, before turning to the women's narratives we first provide an overview of theories of emotion and affect which inform our analysis.

\section{Emotion and Affect}

The concept of affect is tricky to pin down, yet this slipperiness is essential to its definition. Gregg and Seigworth $(2009,2)$ suggest that 'affect is found... in those resonances that circulate about, between, and sometimes stick to bodies and worlds, and in the very passages or variations between these intensities and resonances themselves'. Influenced by 'political, economic and cultural transformations' (Clough and Halley $2007,1)$, the 'affective turn' has signified an extension of and departure from social constructivist approaches to emotion, turning instead to theorists such as Spinoza, Bergson, Deleuze, Guattari and others. Although constructivist accounts of emotion make a lot of sense, and can be easily and justifiably applied to beach bodies, they cannot account for the complex network of possibilities in which emotions exist, and which are enabled via emotions.

Our research on 'beach bodies' is concerned with the relational space between the binary dualisms which are so often presented in geographical thought, and also within society at large. This includes the interplay between nature and culture, inclusion and exclusion, and body and mind. Deleuze understands affect in non-binary terms, that is, as what the body and mind can $d o$ and become, rather than what they are separately and statically (Deleuze and Guattari, 1987, 257). As Probyn (2009, 80-81) explains, 


\section{Deleuze's argument is that emotions and affects are ideas. But they are not}

solely of the mind. They arise out of a violent collision of mind and body. As such they are not, properly speaking, of either; they are a particular combination of thought and body.

The complex notion of affect is perhaps best understood and most useful when it is put into practice, as Julia Coffey does in relation to body work. Coffey's $(2013 ; 2015)$ recent research on body work uses a Deleuzian theorisation to consider the practices of people who change or maintain their bodies (body work), particularly through the use of exercise. Coffey $(2015,621)$ points to the ways that affect allows us to consider the possibilities of bodies, noting that, "the more a body is opened to difference and multiple possibilities for affect, the more force it has; the more it can do'.

New theories of affect open up a focus on relationality. As Coffey $(2015,623)$ points out, 'It is important to move towards theorisations of the body and identity that are capable of addressing the complex, multiple and ambiguous dimensions of embodied subjectivity'. Of course, the place of new and old theories is not separate - they can have complex combinations. While social norms and structures are undoubtedly important to an understanding of beach bodies, affect theory allows for the conception of women's experiences of the beach to be more than the sum of their socially constructed emotions; it allows for a consideration of how women might experience affectual practices, as well as the possibilities of the beach.

\section{Methodology}

Following a feminist cultural epistemology and methodology, this study acknowledges the partiality of knowledge, the importance of power relations, the efficacy of 'everyday knowledges', the need for emancipatory goals for research and the necessity of researcher reflexivity (Ekinsymth 2002, 177). In terms of the latter we reflected on our own embodied experiences of beach going as we designed this study, undertook interviews, analysed data and wrote this paper. Like participants, our own beach 
biographies are emotionally charged. Similarly, the emotions we associate with the beach are multifaceted, shifting and often paradoxical.

Semi-structured interviews of approximately forty-five minutes to an hour were undertaken with ten women to explore the primary research question, 'How do a diverse group of Australian women imagine the beach in relation to national identity, and how does this relate (or not) to their embodied and affective practices of beach-going?'. Such an approach was consistent with our feminist goals of democratising knowledge production, affording women voice and obtaining a detailed, context specific understanding of women's lives (Caretta and Riano 2016). Like Greenleaf, McGreer and Parham's $(2006,189)$ exploratory study of 'physique attitudes and self-presentational concerns', our data were also collected from a relatively small number of one-off interviews. Notably, however, as Crouch and McKenzie $(2006,496)$ argue, small scale research projects are often 'the way in which analytic, inductive, exploratory studies are best done'. Indeed, all participants were pleased to have the opportunity to discuss the topic, and, as such, were highly forthcoming, reflective and insightful, providing detailed accounts of their experiences.

As the study is exploratory, participants were recruited via convenience sampling using our own networks (Mason 2002). At the same time purposeful sampling was also invoked in order to elicit some diversity in the group of interviewees. Following our interest in affect, we were keen to attend to notions of change and continuity in women's experiences of their bodies at the beach. In order to address this issue, we intentionally sought to recruit participants across a range of ages, ethnicities and life stages. The age of participants ranges from 18 to 64. Six of the interviewees are of an Anglo background. The remainder have Jamaican, Vietnamese, Maori and Papuan New Guinea heritage. No Aboriginal or Torres Strait Islander peoples were included in the sample a limitation that is necessary to address in subsequent research given the racialized history of beach culture in Australia. Occupations of participants include undergraduate students, professionals and a retiree. Two of the women are lesbian and the remainder identify as heterosexual. Of the ten interviewees, four are mothers. While all participants 
reside in the state of Queensland, their proximity to, and attendance at the beach was varied.

Cognisant of the multitude of ways in which the beach may be remembered, imagined and experienced, we concentrated interviews on women's experiences of what is referred to as the 'social beach', sometimes referred to as the 'city beach' or 'suburban beach' (Preston-White 2004). These are beaches with a strong social dimension. The most obvious examples of social beaches in Australia are the popular and widely-known Surfers Paradise and Noosa in Queensland or Bondi and Manly in Sydney, New South Wales. In seeking to understand women's experiences of the social beach, we developed an interview schedule/guide which listed the key issues we wished to cover and the central questions around each of these issues (Morris 2015). The choice of interview questions was informed by our knowledge of what was missing from the current literature on the Australian beach - that is, the lived experience of the beach for everyday (non-surfing, non-lifesaving, non-nudist) Australian women. Also informing our approach was the literature on embodiment and affect.

Interviews began by asking participants to reflect on beach going, from childhood to the present (For example; What have been your experiences of the beach? How do you feel when you're at the beach?). Following this, interviewees were questioned about media representations of the beach and the relationship between national identity and the beach (For example; What do you think the beach means to Australians? How do you think the media represents the beach and people who go to the beach?). In the next section of the interview, discussion moved to behaviours associated with beach going and being at the beach (For example; How do you prepare for the beach? As a woman, are there any issues you have with going to the beach?).

Interviews were recorded and transcribed for thematic analysis, following Braun and Clarke's (2006) six step guide as a means to uncover similarities, divergences and patterns. Braun and Clarke's process includes familiarising yourself with the data, generating initial codes, searching for the themes, reviewing the themes, defining and naming themes and producing the report $(2006,87)$. In moving through these steps we worked both individually and collectively, sharing our thoughts, and questioning and 
reflecting on each other's findings (Rapley 2011). Initial codes included, for example, the various emotions and affects which the participants reflected on (including selfconsciousness, embarrassment, frustration, confidence, pleasure and joy), which upon further analysis informed the final theme of 'pride and shame'. The entire process was 'critical, reflexive and iterative' as we repeatedly moved between the transcripts, codes and meanings of codes and themes, as well as the literature and our own beach histories (O’Leary 2014, 275).

Through this analytic process we noticed that women's reflections often focused on the emotional aspects of beach going, specifically the shame and pride which they felt in the beach space. Further to this, the women outlined their affective practices in response to these emotions. Asking women how they feel about their bodies is, in many ways, an intimate exchange (Ellis and Berger 2003, 470). In this case, we were fortunate in that participants brought us into their confidence sharing stories which illuminated the complex interplay between gender, affect and space. As such, they disclosed frustrations, vulnerabilities, resistances and conceits in their embodied experiences of beach going. Thus, in this paper we focus on the affective practices employed by the participants in our study, as they provide an important insight into the ways that affect, gender and space are experienced by women at the Australian beach.

\section{Results and Discussion}

In this section we present three themes that emerged from our analysis. Firstly, the beach as a space of mediation and surveillance. Secondly, women's body work strategies prior to going to the beach and finally, women's body work strategies once at the beach. Participants' experiences were infused with emotion; embarrassment, shame, excitement, pleasure and joy. These emotions were read as expressions of desire, 'Desire here is not a metaphor; it is a method of doing things, of getting places. Desire here is a mode of connection and communication between things...' (Probyn, 1996, 41). This desire, to be seen in a particular way, to make oneself invisible, or to avoid the shame of not meeting mediated notions of the ideal 'beach beauty', becomes the way women negotiate and manage their bodies at the beach. As described below, affects, 
such as pride and shame, are closely implicated in the everyday practices women engage in both before and during beach attendance. Practices such as managing diet, hair removal, awareness of postures and engagement in physical activity are read not as determined by social structures, nor are they simply women's 'choices', but are instead part of the complex gendered assemblages formed in particular spaces (in this case, the beach).

In (i) 'The beach: A space of mediation and surveillance', we consider the participants' awareness of the influence of the media on their experiences of the beach. Women's awareness of watching and being watched is also highlighted. The participants

understood the beach as being a place which is centred around bodies - not just the way bodies are able to 'be' at the beach, but the way that bodies are able to 'look' and 'feel'. This is followed by (ii) 'Body work strategies prior to going to the beach', which outlines the particular practices women engage in prior to going to the beach. These practices and strategies are shown as ways of managing negative emotion (for example, shame) and of supporting positive emotion (for example, pride), although as demonstrated, this is not always straightforward. The final section, (iii) 'Body work strategies at the beach', discusses the major and minor ways women manage emotion at the beach. From subtle posture changes, to avoiding the beach altogether, this section shows the ways our participants consciously worked to place themselves either inside or outside of the frame of the mediated beach body they described.

\section{The beach: A space of mediation and surveillance}

All of the women interviewed were conversant with hegemonic representations of the archetypal beach body in the media (see Small, 2017; Jordan, 2007), and stated that these have a potentially regulatory impact. Julie for example, who has lived on the Gold Coast for three years, described the 'external and extrinsic' pressure of viewing advertisements centred on the beach which reminded her 'of what I'm not'. Similarly, Cathryn, a much younger resident of the Gold Coast observed, 'Well, I don't look like that. I can't go (to the beach) if I don't look the same as all these other people (in the media) do. It gives you real insecurity'. Another participant talked about constantly querying the 'suitability' of her body for the beach in light of media images, while a 
further said her bodily deviations from dominant media representations led her to question whether she had a 'right' to go to the beach. The embodied self-doubt induced by commonly circulating ideas of the 'beach body' had plagued another participant, Joanna, from an early age:

Joanna: Going on holidays to the Sunshine Coast when I was a kid or as a teenager and seeing all of these people that satisfy the iconic image of what an Australian is, I felt that I didn't satisfy that at all. And that made me feel insecure...Coming from Townsville, being pale, not knowing how to surf, not being part of beach culture and feeling really distant from that. And that was something that I admired and looked up to as well, the beach beauty.

Although other beach goers are not physically policing the beach, images of idealised beach beauties are joined by real bodies on the beach in ways that contribute to women's anxieties. For example, the increasing use of beach space as gym space to train and to exercise either alone or in groups (Johansson and Andreasson 2016), was experienced by Tonia as intimidating. She stated:

Tonia: I think that when you are more self-conscious it makes it harder for you to really enjoy the space to the full capacity...I definitely was on the beach feeling as though, 'Mmmm. I don't really belong here.' A feeling of 'Am I quite entitled to be here, with all these really fit people?'.

What Tonia explains is that our bodies are experienced in relation to other people's bodies at the beach. This occurs as we ourselves look at other bodies and compare them with our own, or are looked at by bodies which react to our own. The relationality of beach going bodies is gendered - not only in that women watched and judged other women's bodies at the beach, but also in that men watch and judge women's beach bodies. According to Rita, 'The strongest gaze is the male gaze at the beach, and I think a lot of women shape their experiences at the beach around that'. This is an opinion that resonated with Cathryn who was dismissive of women being viewed as an 'ornament' at the beach. At the same time Cathryn demonstrated the complexity of gendered power relations at the beach volunteering that the bikini is 'empowering' in that it represents a movement away from a 'conservative, patriarchal society'. 
Notably, for Rita and a number of other participants, it was adolescence which first brought awareness of the male gaze and dramatically shifted their affective relationship with the beach. Now 43, Rita recalled turning 13 and the revelation of her body's visibility to men at the beach:

Rita: Having a sense that 'Oh, when I'm at the beach I'm actually some "thing", someone that is viewed, is watched'. You're aware that boys, not necessarily looking at you, but you might observe them watching girls, and you start to learn that you're not that free thing. It changes. You are just-visibility of your body.

Rita's more positive experience of the beach as a child unencumbered by the male gaze, and the power of mediated images (or an obliviousness to them), are themes explored by Green $(2003,110)$ who explains that the 'newly-sexualised (adolescent) subject' experiences the beach differently, for at this juncture it 'becomes a site of competitive and threatening display, redolent with uncertainty and insecurity'. Although Green (2003) observes certain specificities of beach going practices for men and women (for example, women's body hair removal), her analysis is not specifically concerned with the gendered experiences of beach-going.

In this study, women were not only aware of being watched by others, but they were also voyeurs themselves, critical of both other women's bodies and their own in comparison. Several of the participants described other women's embodied beach presence in disparaging terms, utilising verbs such as 'flaunted' and 'paraded', but then offered caveats regarding women's prerogative to do so freely. Illustrative was Tonia's observation that there is a 'trophy mentality' for some women at the beach in that for them it was a 'time to show off all my hard work'. Interestingly, Tonia quickly qualified this statement noting that their 'hard work' earned them the 'right' to do so. In this statement, and other equivalent comments, participants conveyed a deep sense of ambivalence about women's embodied beach performance. They both lamented and participated in the gaze, and both decried and validated bodily performances by women at the beach.

\section{Body work strategies prior to going to the beach}


As well as demonstrating a highly attuned awareness of bodies in the space of the beach, participants also explained their attempts to control their own bodies prior to even stepping foot onto the sand. Preparations for the beach varied widely depending on the type of beach experience the participants expected to have. Amy, who does not consider herself a 'beach person', exemplified the way women's practices differed according to which beach they were visiting and why they were visiting. She stated that for local visits to the beach she would 'probably skip breakfast so that I'm not bloated', but also noted that she had recently started going to the gym to prepare her body for a beach holiday with her boyfriend in six months. Small's (2016, 24-25) 'holiday body' study described a similar variety in practices, where 'Different destinations and types of holiday had different meanings as to how one should look in that space and how much work was required to get "that look". Although Amy's preparations may seem extreme, the fact that she does not consider herself a 'beach person' points to the pressure that women can feel to achieve the 'beach body' stereotype.

Another participant's experience of attaining the 'beach body' reflected a different expression of the pressure women feel to have a 'beach body'. Melissa stated that getting 'beach body ready' was a phrase she and her girlfriends used 'a lot' when talking about exercising or getting fit. In this way, her body work was not solely for the beach, but the beach was a place where she could experience the rewards of having a body which is 'ready' - or has been appropriately prepared - to be there. In Coffey's (2015, 614) research on body work she sees these practices as 'crucial to identity'. This was also evident in Melissa's experience of having her 'boobs done', noting that it 'definitely helps as far as what I look like in less clothes... I definitely think, "hey, let's go to the beach and get these out there",. The affects which are experienced by women in relation to their breasts at the beach is reflected in a study by Sischo and Martin $(2015,89)$, who report that one participant's difficult decision not to have breast surgery left her feeling 'bad' when her breasts were more exposed at the beach. Where health and beauty are not always aligned, as in the example from Sischo and Martin's (2015) research, women can feel negative about their appearance, rather than feel positive about their health. 
A critical component of getting ready for the beach revolves around body hair. All of the women spoke about what Julie termed the 'hairless factor', and while some said that they might not bother with hair-removal for a quiet beach, the majority would remove at least their leg and underarm hair for a busier or more social beach. More problematic than arms and legs was the pubic region, to which Melissa's motto was, 'If there's a fro, there's no go'. In Braun, Tricklebank and Clarke's (2013) research on body hair, which is fittingly titled, 'It shouldn't stick out from your bikini at the beach', the authors cite wearing a swimsuit as a key reason given for women's pubic hair removal. Aside from removing pubic hair (either in its entirety or only outside the 'bikini line'), participants also engaged in other strategies to minimise its visibility. For example, Rosalind wears boy leg-style bikini bottoms to avoid exposing 'extraneous things' and Joanna dresses in shorts with her bikini top, stating that, 'I have so much hair to remove from my pubic area that I just don't do it'. By adapting what they wore at the beach, both Joanna and Rosalind were able to feel comfortable with both the Australian practice of wearing a bikini, and the acceptable norm of hairlessness on the beach.

The choice of what to wear on the beach was another important strategy to avoid embarrassment for many of the participants. Amy noted that before going to the beach she would try on her swimwear in front of the mirror, 'to make sure I'm ok'. While participants were aware of what was appropriate 'in society's eyes', many attempted to avoid visibility as much as possible. For Karen this involved wearing items of clothing that 'hide the bulges' to avoid being 'eaten alive by stares'. Similarly, Cathryn described that prior to weight-loss she would wear long skirts in order to 'hide and conceal' her body, because it made her feel 'safer' from judgement. In this way, the participants' acute awareness of being watched at the beach prompted their attempts to make their bodies as invisible as possible, using their choice of clothing and swimwear as a strategy for avoiding judgement and shame.

\section{Body work strategies at the beach}

The desire for invisibility was the main reason participants deployed strategies once at the beach itself. The act of 'lying' on the beach for example, was a practice which some of the participants enjoyed as relaxing (and it is worth noting that only one of the 
women spoke of lying on the beach for the purpose of sun-tanning), while others avoided it altogether, because they saw it as a deliberate display of their bodies. Karen stated that she 'didn't really lie on the beach' because she didn't feel 'comfortable showing [her body] off to anyone'. In another interview, Tonia explained that one of the reasons she is able to be comfortable on the beach is 'because I'm not laying back on the beach showing off my body'. Young $(2005,142)$ argues that women's bodily movements are often characterised by the 'failure to make full use of the body's spatial and lateral potentialities'. This claim was supported by the numerous ways women in this study worked to cover up, limit exposure or make invisible their bodies.

Participants also described other mannerisms and movements which they consciously altered in the beach space. Julie stated that she would be 'guarded' and 'have a different code of behaviour' because she would 'not be wanting to be spotted bare, in almost nudity'. Similarly, Amy described how her 'walking might be different' and she might have her 'arms crossed' or be 'fiddling with things'. Indeed, Amy's awareness of her body affected almost all of her movements at the beach,

Amy: I'm not moving as freely as I would if I was fully clothed. Say I wanted to bend down or something, I'd think twice about where I'm moving, how I'm moving, in case some parts of me twist in a way I don't like, or I don't like the way it looks in my head. So I feel like it restricts me more, because I'm not presented in a way I wanna be.

This quotation highlights the ways that beach-going is embodied, and, at the same time, how the experience is also imagined in relation to the way Amy wants to be presented. Her movements and way of being are not natural, but rather are performed according to the imagined 'beach body'.

As well as avoiding certain mannerisms or movements, the participants also used other strategies to conceal their bodies. One such strategy was the purposeful engagement of a towel, which was used by Amy to cover a 'big belly' when sitting down, and by Karen to 'cover my private part, my belly and my bottom'. Rita also described the 'strategy of the towel', 
Rita: If you go for a swim, you leave your towel on as long as possible, drop it right before the waves, have the towel strategy for post-getting out, knowing that, 'ok, my towel's there, I haven't got that far to walk without any coverage'.

Like Rita, Nadia also referred to the towel as part of the strategy of what she likened to a 'walk of shame' between the beach and the water. Once in the water though, Nadia stated that when "no one can see your body... self-conscious feelings dissipate for a time'. Likewise, Tonia felt that 'when you enter the water, you do come into a space of "we're all the same" because your body isn't really on show'. For Rita, Nadia and Tonia, the ocean provided 'coverage' and therefore a safe space in which their bodies were able to experience the pleasures of the beach.

Although swimming in the ocean provided a certain safety for some of the participants, for others the water presented risks. They were not concerned about risks as manifest in sharks, rips or jellyfish but as manifest in self-consciousness about the impact of wet hair. Amy noted she was concerned about her hair being 'disgusting after the water', and therefore brought hair products to the beach so she could afterwards rectify its look if she decided to enter the water. Similarly, Melissa felt 'attractive at the beach', but admitted that 'I haven't swum in the beach much at all', because she felt that 'getting my hair wet was embarrassing', and 'I can't trust my appearance or how I look after that... so that is a massive anxiety for me'. For Melissa, whose mother is Papua New Guinean, this anxiety was because 'growing up on the Gold Coast I always looked different... so it's always been a massive thing'. Melissa's anxiety also echoes Lobo's (2014) findings on the affective tensions of racialised beach experiences. Avoiding the ocean, (which some would consider a major drawcard of the beach experience), is therefore a strategy which allows some women to escape shame and self-consciousness at the beach.

\section{Conclusion}

This paper has added a new dimension to textual studies of 'the beach body' undertaken by Jordan (2007) and Small (2017). It has provided empirical evidence to support the 
respective authors' concerns that exclusionary images may severely circumscribe women's leisure pursuits and limit their enjoyment of such pursuits. Of course, the idea that leisure is not a simple matter of enjoyment is not new (see Wearing 1998); we have to work for our leisure time - and not just to save enough money to take a holiday.

However, for Australian women the beach represents a site where leisure and labour are inextricably intertwined. Women are aware that they must work on either their bodies, (so as to make them acceptable for public display and thus avoid shame), or otherwise work on their sense of self-confidence (in order to feel proud of themselves for the bravery it took to be at the beach without adhering to a beach 'ready' body). In other words, at the beach women must either make themselves appropriately visible or appropriately invisible. Frith et al. $(2014,174)$ note that 'social recognition and selfhood are repeatedly read on the body in the form of cultural literacy which rewards a self that works itself into its frames of cultural knowingness'. As such, the cultural knowledge which women hold about what a beach-going female looks like and does, enables them to engage in various strategies to feel more comfortable with their bodies in the beach space.

Although the participants felt that these strategies 'allowed' them to be comfortable at the beach, they also restricted the women's movements, removed the possibility of an unplanned, spontaneous beach encounter and, moreover, hindered the possibility of an embodied beach experience which is not tethered to one's body image. As such, 'the affects related to these body work practices are limited' (Coffey 2015, 620). The beach body is assembled both in the space of the beach and in our imagination of it, and, as such, part of the preparation for the experience is physical, while it is also emotional. Fox $(2015,313)$ suggests, 'What bodies can feel is an element of what they can do'. As demonstrated here, many women's experiences of the beach are limited (in some cases dramatically) because of feelings of shame and related affects. Yet their desire for enjoyment and connection to the beach is clear as they continue to 'work' at a range of strategies to make their experience more bearable, comfortable, enjoyable and pleasurable. 


\section{References}

Barcan, R. 2001. "The moral bath of bodily unconsciousness: Female nudism, bodily exposure and the gaze." Continuum: Journal of Cultural and Media Studies, 15 (3): 303-317.

Booth, D. 2001. Australian Beach Cultures: The History of Sun, Sand and Surf. London: Routledge.

Braun, V., and Clarke, V. 2006. 'Using thematic analysis in psychology', Qualitative Research in Psychology, 3: 77-101.

Braun, V., Tricklebank, G., and Clarke, V. 2013. "It shouldn't stick out from your bikini at the beach: Meaning, Gender, and the Hairy/Hairless Body." Psychology of Women Quarterly. 37 (4): 478-493.

Caretta, M. A., and Riano, Y. 2016. "Feminist participatory methodologies in geography: creating spaces of inclusion.” Qualitative Research. 16 (3): 258-266.

Clough, P. T., and Halley, J., eds. 2007, The Affective Turn: Theorizing the Social, Durham: Duke University Press.

Coffey, J. 2013. "Bodies, body work and gender: Exploring a Deleuzian approach." Journal of Gender Studies. 22 (1): 3-16.

Coffey, J. 2015. “As long as I'm fit and a healthy weight, I don't feel bad: Exploring body work and health through the concept of 'affect." Journal of Sociology. 51 (3): 613627.

Craik, J. 2010. "Swimwear, surfwear, and the bronzed body in Australia." In Berg encyclopedia of world dress and fashion, edited by Eicher, J.B. Oxford: Berg.

Crombie, I. 2004. Body Culture. Mulgrave: Peleus Press.

Crouch, M., and McKenzie, H. 2006. "The logic of small samples in interview-based qualitative research.” Social Science Information. 45 (4): 483-499.

Deleuze, G., and Guattari, F. 1987. A Thousand Plateaus: Capitalism and Schizophrenia. Minneapolis: University of Minnesota Press. 
Duncan, M., and Klos, L. 2014. "Paradoxes of the Flesh: Emotion and Contradiction in Fitness/Beauty Magazine Discourse”, Journal of Sport and Social Issues. 38 (3): 245262.

Ekinsmyth, C. 2002. "Feminist cultural geography" in Doing Cultural Geography, edited by P. Shurmer-Smith, 53-66. London: Sage.

Ellis C., and Berger, L. 2003. "Their story/my story/our story” in Inside Interviewing: New Lenses, New Concerns, edited by Holstein, J. and Gubrium, J. Thousand Oaks: Sage.

Ellison, E 2013, “The Australian beachspace: flagging the spaces of Australian beach texts", PhD diss., Queensland University of Technology.

Fernandez, S. 2012. "Relationships between self-esteem, media influence and drive for thinness.” Eating Behaviors: An International Journal. 13 (4): 321-325.

Fiske, J., Hodge, B., and Turner, G. 1987. Myths of Oz: Reading Australian Popular Culture. St Leonards: Allen and Unwin.

Fox, N.J. 2015. "Emotions, affects and the production of social life." The British Journal of Sociology. 66 (2): 301-318.

Frith, H., Raisborough, J., and Klein, O. 2014. "Shame and pride in how to look good naked.” Feminist Media Studies. 14 (2): 165-177.

Green, L. 2003. "Perfect imperfection: feeling cool on the nude beach." in Some like it hot: The beach as a cultural dimension, edited by Skinner, J., Gilbert, K., and Edwards, A. Aachen: Meyer and Meyer Sport.

Greenleaf, C., McGreer, R., and Parham, H. 2006. Physique attitudes and selfpresentational Concerns: Exploratory interviews with female group aerobic exercisers and instructors." Sex Roles. 54 (3/4): 189-199.

Gregg, M. and Seigworth, G. J., eds. 2009. The Affect Theory Reader. Durham: Duke University Press. 
Hartley, J., and Green, J. 2006. "The public sphere on the beach.” European journal of Cultural Studies. 9 (3) 341-362.

Johansson, T., and Andreasson, J. 2016. "The gym and the beach: globalization, situated bodies, and Australian fitness." Journal of Contemporary Ethnography. 45 (2) 143-167.

Jordan, F. 2007. "Life's a beach and then we diet: Discourses of tourism and the 'beach body' in UK Women's Lifestyle Magazines." in Tourism and Gender, edited by A.

Pritchard, N. Morgan, I. Ateljevic., and C. Harris. Oxfordshire: CABI.

Khamis, S. 2010. "Braving the burqini: rebranding the Australian beach.” Cultural Geographies. 17: 379-390.

Lambert, A. 2010. “(Re)producing country: mapping multiple Australian spaces.” Space and Culture. 13 (3): 304-314.

Lobo, M. 2014. "Affective energies: sensory bodies on the beach in Darwin, Australia." Emotion, Space and Society. 12: 101-109.

Lean, G., and Staiff, R. 2016. "Current developments in the geographies of leisure and tourism." Travel and Imagination. Farnham: Routledge.

Mason, J. 2002. Qualitative Researching. London: Sage Publications.

McMahon, J., and Dinan-Thompson, M. 2011. "Body work-regulation of a swimmer body: An autoethnography from an Australian elite swimmer." Sport, Education and Society, 16 (1): 35-50.

McMahon, J., Penney, D., and Dinan-Thompson, M. 2012. "Body practices-exposure and effect of a sporting culture?: Stories from three Australian swimmers." Sport, Education and Society. 17 (2): 181-206.

Metusela, C., and Waitt, G. 2012. Tourism and Australian Beach Cultures: Revealing Bodies. Bristol: Channel View Publications.

Morris, D. 2015. A Practical Guide to In-depth Interviewing. London: Sage. 
Nash, M. 2016. "White pregnant bodies on the Australian beach: a visual discourse analysis of family photographs." Journal of Gender Studies. Advance online publication. doi: 10.1080/09589236.2016.1264297

Noble, G., and Poynting, S. 2010. "White lines: the intercultural politics of everyday movement in social spaces." Journal of intercultural studies. 31 (5): 489-505.

O’Leary, Z. 2014. The Essential Guide to Doing Your Research Project, London: Sage Publications.

Perloff, R. 2014. "Social media effects on young women's body image concerns: theoretical perspectives and an agenda for research.” Sex Roles. 71 (11-12): 363-377. Pettigrew, S. 2002. "Australians and their leisure time", in Asia Pacific Advances in Consumer Research Volume 5, edited by Ramizwick, Tu Ping, and Valdosta, Association for Consumer Research, 108-112, viewed 23 October 2016, $<$ http://acrwebsite.org/volumes/11772/volumes/ap05/AP-05>

Preston-Whyte, R. 2004. "The beach as a liminal space." in A Companion to Tourism, edited by A. Lew, C. M. Hall and A. M. Williams. Malden: Blackwell Publishing.

Probyn, E. 1996. Outside Belongings. New York: Routledge.

Probyn, E. 2009. 'Writing shame', in The Affect Theory Reader, edited by Gregg, M., and Seigworth, G.J. Durham: Duke University Press.

Rapley, T 2011, 'Some pragmatics of data analysis' in Qualitative Research, edited by Silverman, D., 273-290. London: Sage.

Schmidt, C. 2012. The Swimsuit. London: Berg.

Sischo, L., and Martin, P. Y. 2015. "The price of femininity or just pleasing myself? Justifying breast surgery." Gender Issues. 32 (2): 77-96.

Small, J. 2016. "Holiday bodies: Young women and their appearance." Annals of Tourism Research. 58: 18-32.

Small, J. 2017. "Women's “beach body" in Australian women's magazines." Annals of Tourism Research. 63: 23-33. 
Wearing, B. 1998. Leisure and Feminist Theory. London: Sage Publications.

Young, I. M., 2005. On female body experience:" Throwing like a girl" and other essays. Oxford: Oxford University Press. 